\title{
Deformation and seismicity in the Coso geothermal area, Inyo County, California: Observations and modeling using satellite radar interferometry
}

\author{
Yuri Fialko and Mark Simons \\ Seismological Laboratory, California Institute of Technology, Pasadena
}

\begin{abstract}
Interferometric synthetic aperture radar (InSAR) data collected in the Coso geothermal area, eastern California, during 1993-1999 indicate ground subsidence over a $\sim 50 \mathrm{~km}^{2}$ region that approximately coincides with the production area of the Coso geothermal plant. The maximum subsidence rate in the peak of the anomaly is $\sim 3.5 \mathrm{~cm} \mathrm{yr}^{-1}$, and the average volumetric rate of subsidence is of the order of $10^{6} \mathrm{~m}^{3} \mathrm{yr}^{-1}$. The radar interferograms reveal a complex deformation pattern, with at least two irregular subsidence peaks in the northern part of the anomaly and a region of relative uplift on the south. We invert the InSAR displacement data for the positions, geometry, and relative strengths of the deformation sources at depth using a nonlinear least squares minimization algorithm. We use elastic solutions for a prolate uniformly pressurized spheroidal cavity in a semi-infinite body as basis functions for our inversions. Source depths inferred from our simulations range from 1 to $3 \mathrm{~km}$, which corresponds to the production depths of the Coso geothermal plant. Underpressures in the geothermal reservoir inferred from the inversion are of the order of 0.1-1 $\mathrm{MPa}$ (except a few abnormally high underpressures that are apparently biased toward the small source dimensions). Analysis of the InSAR data covering consecutive time intervals indicates that the depths and/or horizontal extent of the deformation sources may increase with time. This increase presumably reflects increasing volumes of the subsurface reservoir affected by the geothermal exploitation. We show that clusters of microearthquakes associated with the geothermal power operation may result from perturbations in the pore fluid pressure, as well as normal and shear stresses caused by the deflation of the geothermal reservoir.
\end{abstract}

\section{Introduction}

Many natural and man-induced processes result in injection and withdrawal of fluids in the Earth's interior. Examples include migration of magmatic fluids at depth, oil and gas recovery, liquid waste disposal, and geothermal energy production. These processes are commonly accompanied by deformation of the host rocks. When such deformation can be detected and monitored, it may provide important insights about the extent, morphology, and dynamics of subsurface fluid reservoirs. Interferometric synthetic aperture radar (InSAR) techniques provide a unique opportunity to infer the host rock deformation induced by fluid migration at depth by measuring displacements of the Earth surface over the areas of interest [e.g., Massonnet et al., 1997; Rosen et al., 1996; Fielding et al., 1998]. Unlike other geodetic methods that rely on essentially point mea-

Copyright 2000 by the American Geophysical Union.

Paper number 2000JB900169.

0148-0227/00/2000JB900169\$09.00 surements at the Earth surface, InSAR readily provides surface displacement maps having large spatial coverage $\left(>10^{4} \mathrm{~km}^{2}\right.$ ), high spatial resolution (up to several meters), and accuracy of the order of $1 \mathrm{~cm}$ [Goldstein et al., 1993; Massonnet and Feigl, 1998]. This paper is a case study of crustal deformation associated with geothermal production in the Coso geothermal area, central eastern California, inferred using the interferometric synthetic aperture radar observations.

The Coso geothermal field is located in central eastern California between the southern Sierra Nevada and Argus Range (Figure 1). Tectonically, this area corresponds to the transition zone between the strike-slip San Andreas fault and extensional Basin and Range province [Walter and Weaver, 1980; Roquemore, 1980]. This area has experienced intense magmatism during the last several million years [Duffield et al., 1980], with local topography dominated by numerous rhyolitic domes and lava flows. Cenozoic volcanic rocks and shallow alluvial deposits overlie Mesozoic basement composed mostly of granitic and metamorphic rocks. Results of K-Ar dating indicate that volcanic activity has 


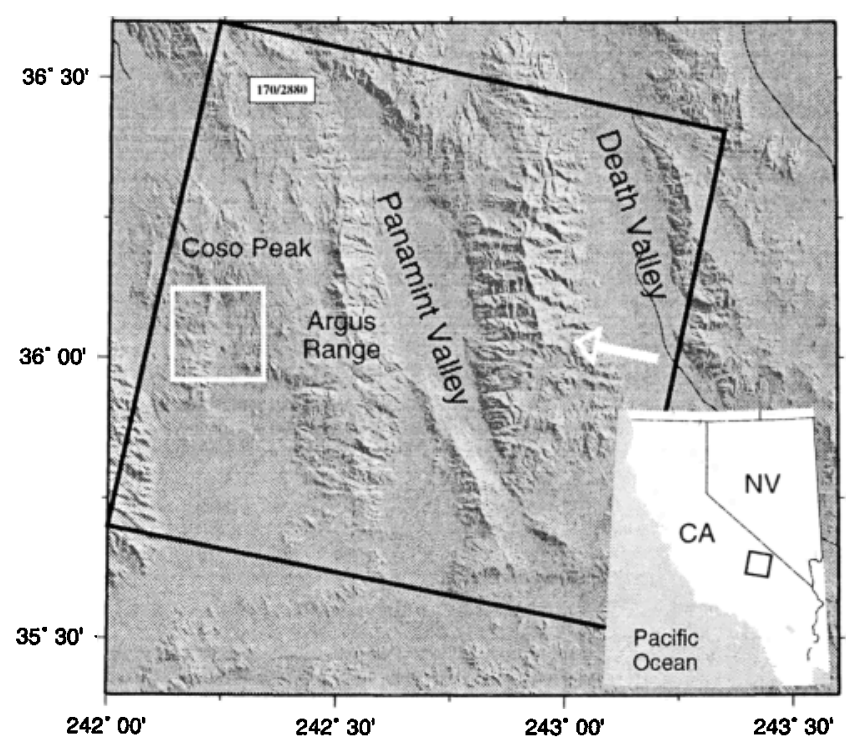

Figure 1. Geographic setting of the area of study. Solid squares on the topographic map and in the inset show the area of the ERS radar image (track 170, frame 2880 , descending orbit). White arrow indicates the satellite radar look direction. White rectangle outlines the Coso geothermal area (shown in detail in Figure 3). For the Coso area, projections of a unit vector toward the satellite onto the east, north, and up axes are $0.38,-0.09$, and 0.92 , respectively.

persisted in this area since $4 \mathrm{Ma}$, with the youngest volcanics erupted as recently as 40,000 years ago [Lanphere et al., 1975; Duffield et al., 1980]. Radiometric ages of the volcanic rocks, together with surface geothermal phenomena [Austin and Pringle, 1970], high heat fluxes [Combs, 1980], and increased attenuation and reduced velocities of the seismic waves in the upper to middle crust [Reasenberg et al., 1980; Young and Ward, 1980] are interpreted as indicating the existence of a long-lived magmatic system beneath the Coso area. This magmatic system is thought to be a primary heat source for the Coso geothermal field [Smith and Shaw, 1975; Duffield et al., 1980].

Geothermal resources in the Coso area are actively exploited. Owned by the U.S. Navy, the Coso geothermal plant is the second largest in the United States with an annual energy output of $300 \mathrm{MW}$. Geothermal recovery began in 1987, resulting in more than 200 development wells [Wohletz and Heiken, 1992]. Production involves reinjecting the extracted geothermal fluids back into the underground reservoir and is associated with intense microseismicity [Feng and Lees, 1998]. The microearthquakes are presumably induced by pressure perturbations due to fluid circulation within the geothermal system [Pearson, 1981; Fehler, 1989; Feng and Lees, 1998], although particular relationships between seismicity and plant operation are poorly understood. Because the Coso geothermal plant is located in a tectonically active area, separation of microseismicity induced by the geothermal production from the "background" seismicity due to tectonic stresses is a difficult task. The Coso region is one of the most seismically active areas in southern California [Walter and Weaver, 1980; Hauksson et al., 1995]. More than 7000 earthquakes with body wave magnitudes $m_{b}$ from 0 to $5+$ have been recorded in the region from 1980 to 1998 by the Southern California Seismic Network operated by the Caliornia Institute of Technology and the U.S. Geological Survey. Most earthquakes occur at depths of 1 to $8 \mathrm{~km}$ in a zone striking approximately north to south [Walter and Weaver, 1980; Roquemore, 1980]. Focal mechanisms indicate NNE normal, NW right-lateral, and NE left-lateral faulting, consistent with active westeast extension in the area. As we shall demonstrate in sections 3 and 4, surface deformation measured by InSAR may be used to delineate the areas affected by stress perturbations due to geothermal production and to help to understand possible causative links between the geothermal plant operation and observed seismic activity.

\section{Data Processing}

We use radar images acquired by the European Space Agency satellites, ERS-1 and -2, between July 1993 and July 1998. The synthetic aperture radar (SAR) images produced by the ERS satellites consist of an amplitude and phase of a backscattered radar signal at a wavelength of $5.6 \mathrm{~cm}$. A difference in radar phase between two subsequent SAR acquisitions (i.e., an interferogram) may be used to detect a relative motion between the satellite and the Earth's surface during the time interval between the data collection. (For an introduction to the InSAR method, see Gabriel et al. [1989], Goldstein et al. [1993], and Massonnet and Feigl [1998].) The Coso area is well-suited for study using InSAR because it is located in an arid semidesert environment with little or no vegetation, so that the surface reflectivity is sufficiently high, and the reflectivity pattern does not significantly change with time. Inspection of the ERS data indicates that the radar scenes in the area maintain correlation over time intervals as long as 6 years (i.e., for a total period of observations between 1993 and 1999). The geographic location of the radar scene used in this study and the radar acquisition dates are shown in Figures 1 and 2.

The raw ERS data were processed using the Jet Propulsion Laboratory (JPL)/Caltech software package ROI_PAC. Both "two-pass" and "four-pass" interferometric techniques were employed in our analysis. In the two-pass method, effects of the topography on interferometric fringes are removed using a digital elevation model (DEM) [Zebker and Goldstein, 1986]. Because the topography variations in the Coso area are substantial, with elevation changes of more than $1 \mathrm{~km}$, a good DEM model is essential for the two-pass data processing. We concatenated a digital elevation model for 


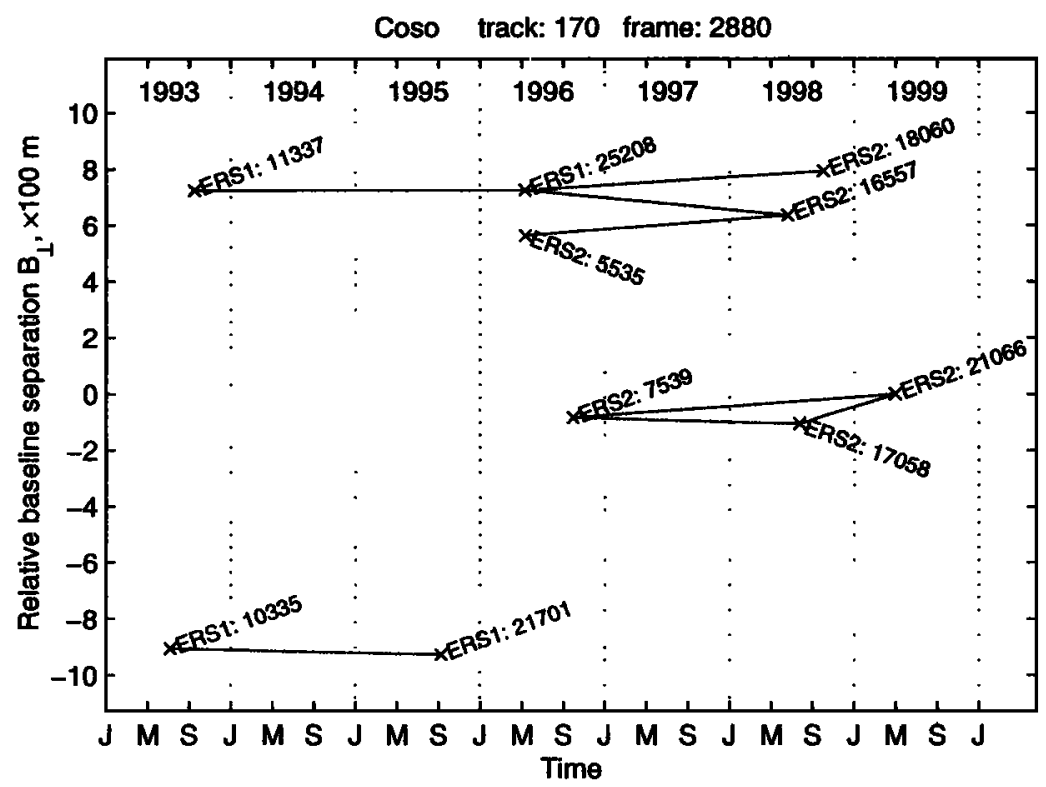

Figure 2. ERS radar acquisitions used in this study. Horizontal axis is time in years and months ( $\mathrm{J}$, January; M, May; S, September), and vertical axis is the across-track distance between the satellite orbits, in hundreds of meters, referenced to the most recent radar scene (May 1, 1999). Crosses mark acquisition dates, labels denote respective satellite and orbit numbers, and lines connect interferometric pairs used in this study. The maximum baseline separation for the interferometric pairs shown is $104 \mathrm{~m}$, which corresponds to an ambiguity height (i.e., a topographic relief capable of generating one interferometric fringe [e.g., Zebker and Goldstein, 1986]) of $\sim 100 \mathrm{~m}$.

the Coso area from 81 USGS 7.5 min digital elevation maps (see Figure 3). In the four-pass method, topographic effects are removed using an additional shortterm interferometric pair [Gabriel et al., 1989; Goldstein et al., 1993]. In our four-pass data processing topographic corrections are made using two InSAR pairs acquired in a "tandem mode" on October 13-14, 1995, and May 10-11, 1996, respectively. We find that both two-pass and four-pass techniques give rise to essentially similar results, which implies that the digital elevation model used is sufficiently accurate. This conclusion is confirmed by the absence of any topography-correlated fringes on a short-term InSAR pair May 10-11, 1996 (see Figure 2) processed using a two-pass technique. After corrections for topography, the major factor limiting measurements of surface deformation is a variability in atmospheric conditions (e.g., a moisture content in the troposphere) [Goldstein, 1995; Zebker et al., 1997]. Because of their essentially random nature, atmospheric effects are difficult to account for. In practice, interferometric fringes produced by a long-term surface deformation may be distinguished from those due to the (presumably short-term) atmospheric "noise" by analyzing signal persistence in a particular area over (1) several consecutive interferograms, and/or (2) several "simultaneous" interferograms spanning approximately the same time interval [Goldstein, 1995; Massonnet and Feigl, 1995; Tarayre and Massonnet, 1996]. Below we report the results obtained using the two-pass method only (note that the four-pass interferograms may in- herit atmospheric anomalies from an interferometric pair used for topographic corrections).

Plate 1 shows deformation observed in the Coso geothermal area between 1993 and 1998. Ground motion

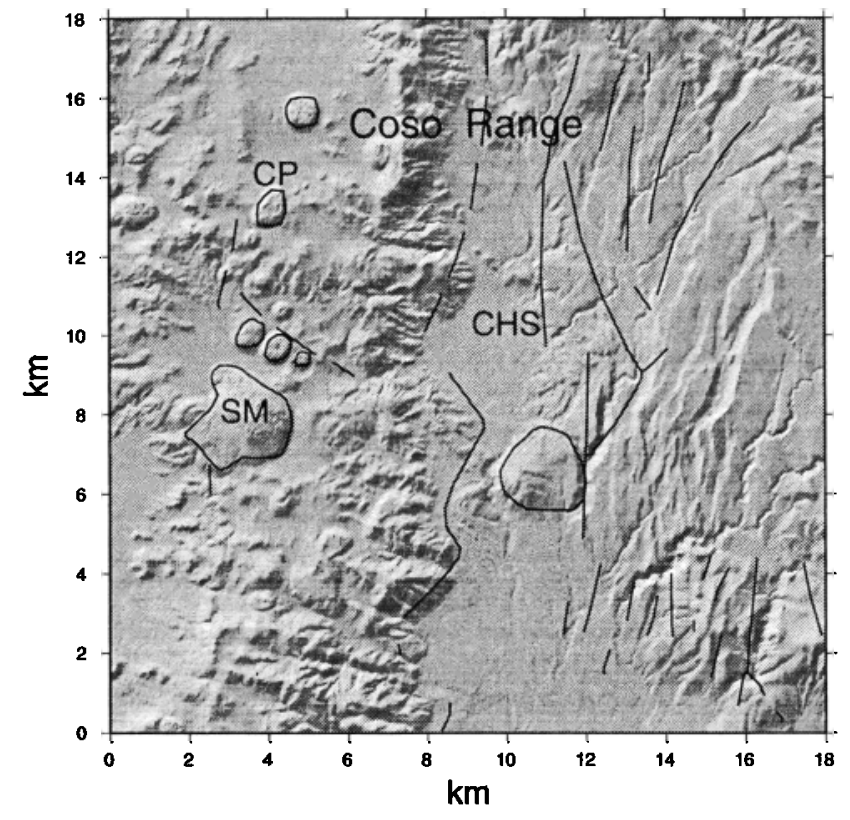

Figure 3. Shaded relief map of the Coso area. Coordinates of the origin are $35^{\circ} 57^{\prime} 37^{\prime \prime} \mathrm{N}, 117^{\circ} 51^{\prime} 36^{\prime \prime} \mathrm{W}$. SM, Sugarloaf Mountain; CP, Cactus Peak; CHS, Coso Hot Springs. Thin solid lines mark some rhyolitic domes and known faults. The main production area of the Coso geothermal plant is to the east of Sugarloaf Mountain. 
detected by InSAR is a projection of surface displacements onto the line of sight of the satellite. Because the satellite look direction has a steep incidence angle ( $\sim 23^{\circ}$ from vertical for the area of study) and because of the expected nature of deformations in a geothermal area, the line of sight displacements shown in Plate 1 may be interpreted as reflecting mostly vertical motions of the ground. The same interferometric pattern is seen on all long-term interferograms analyzed (see Figure 2). The size and sign of the observed anomaly indicate ground subsidence in the region of $\sim 50 \mathrm{~km}^{2}$, approximately coinciding with the production area of the Coso geothermal plant. Interferograms shown in Plate 1 suggest that the subsidence rate may be nearly steady state, with maximum subsidence rate in the peak of the anomaly of $3-4 \mathrm{~cm} \mathrm{yr}^{-1}$ and volumetric subsidence rate of the order of $\sim 10^{6} \mathrm{~m}^{3} \mathrm{yr}^{-1}$. Note that because the phase difference is a relative measure of ground motions, the radar's line of sight displacements are defined up to an arbitrary constant. In Plate 1 we choose this arbitrary constant such that the line of sight displacements on the periphery of the inferred subsidence anomaly are approximately zero. As can be seen in Plate 1 , the anomaly is consistent in the interferograms that overlap in time (compare Plates 1a and 1c to $1 \mathrm{~b}$ and $1 \mathrm{~d}$ ). Some of the differences between the interferograms that cover similar time intervals may be due to atmospheric effects. In particular, atmospheric effects seem to be responsible for essentially random perturbations in the radar phase difference along the edges of the InSAR images shown in Plate 1. Otherwise, overall similarity of the observed signal on the respective simultaneous pairs highlights systematic changes in the anomaly pattern with time (e.g., compare Plates 1c and 1d). In particular, the two largest subsidence peaks in the western and northern part of the anomaly seem to broaden, and perhaps even to merge with time. This evolution of the deformation anomaly is quantified in section 3 and further discussed in section 4. Another expression of time-dependent deformation in the Coso geothermal area is a progressive expansion of the subsidence anomaly to the south of the main production area (Plates $1 \mathrm{~b}$ and $1 \mathrm{~d}$ ). This southward expansion of subsidence is seen in all InSAR images acquired after 1995 except in the July 25, 1998/September 28, 1996, interferometric pair (not shown) where this subsidence is less conspicuous, presumably because of the atmospheric effects .

\section{Modeling and interpretation}

The simplest model relating ground surface deformations to volume changes at depth is an isotropic point pressure source in a uniform elastic half-space [Mogi, 1958]. Point pressure sources have been widely used to interpret surface displacements due to various processes involving fluid pressurization at depth [e.g., Davis, 1986; Lanari et al., 1998; Carnec and Fabriol,
1999]. However, ground displacements as inferred from the InSAR data in the Coso geothermal area (Plate 1) exhibit a pattern that is too complicated to be explained in terms of a point source model. In particular, all four interferograms shown in Plate 1 indicate that the deformation region is irregular, with several essentially nonaxisymmetric peaks of subsidence and at least one area of relative uplift (trending north-south near the southern edge of the subsidence bowl). To test how well different models are able to explain the observed deformation pattern we performed nonlinear inversions of the InSAR data employing multiple isotropic point sources [Mogi, 1958] and finite prolate spheroidal sources [Yang et al., 1988]. Results of our simulations are summarized in Table 1. Table 1 shows the mean square misfit $R(\mathrm{M})$ that minimizes the $L_{2}$ norm [Press et al., 1992, p. 682]

$$
R(\mathbf{M})=\frac{1}{n-m} \sum_{i=1}^{n}\left(\frac{y_{i}-f\left(x_{i}, \mathbf{M}\right)}{\sigma_{i}}\right)^{2},
$$

where $\mathbf{M}$ is the model parameters' vector having length $m, n$ is the number of data points, $y$ is the data vector, $f$ is the model prediction at a given point $x_{i}$, and $\sigma_{\imath}(i=1, n)$ are individual standard deviations of $y_{\imath}$, or data weights. Unfortunately, uncertainties in the radar line of sight displacement measurements (essentially $\sigma_{i}$ ) cannot be readily estimated. Therefore in our calculations we used $\sigma_{i}=$ const $=\sigma$. A particular value of $\sigma$ was chosen such that the mean square misfit $R$ is of the order of unity for the best fitting model; this gives rise to $\sigma \sim 0.3 \mathrm{~cm}$ (see Table 1). These values of $\sigma$ are of the same order as the amplitude of highfrequency noise present in most of the interferograms (see Plates 2d and 3d), presumably due to atmospheric effects. This correspondence is consistent with a large fraction of the InSAR measurement errors being due to variations in the atmospheric conditions.

Table 1. Mean Square Misfit $R$ (Equation (1))

\begin{tabular}{|c|c|c|}
\hline $\begin{array}{l}\text { Number of } \\
\text { Sources } N\end{array}$ & Mogi Source & Prolate Spheroid \\
\hline \multicolumn{3}{|c|}{ Interferometric Pair May 10, 1996/September 15, $1993^{\circ}$} \\
\hline 1 & 7.18 & 4.58 \\
\hline 2 & 3.79 & 2.16 \\
\hline 3 & 3.62 & 1.52 \\
\hline 4 & 1.96 & 1.06 \\
\hline 5 & 1.50 & 0.93 \\
\hline \multicolumn{3}{|c|}{ Interferometric Pair October 3, 1998/May 10, $1996^{\mathrm{b}}$} \\
\hline 1 & 5.15 & 3.49 \\
\hline 2 & 2.75 & 1.63 \\
\hline 3 & 2.00 & 1.29 \\
\hline 4 & 1.53 & 1.17 \\
\hline 5 & 1.35 & 1.11 \\
\hline
\end{tabular}



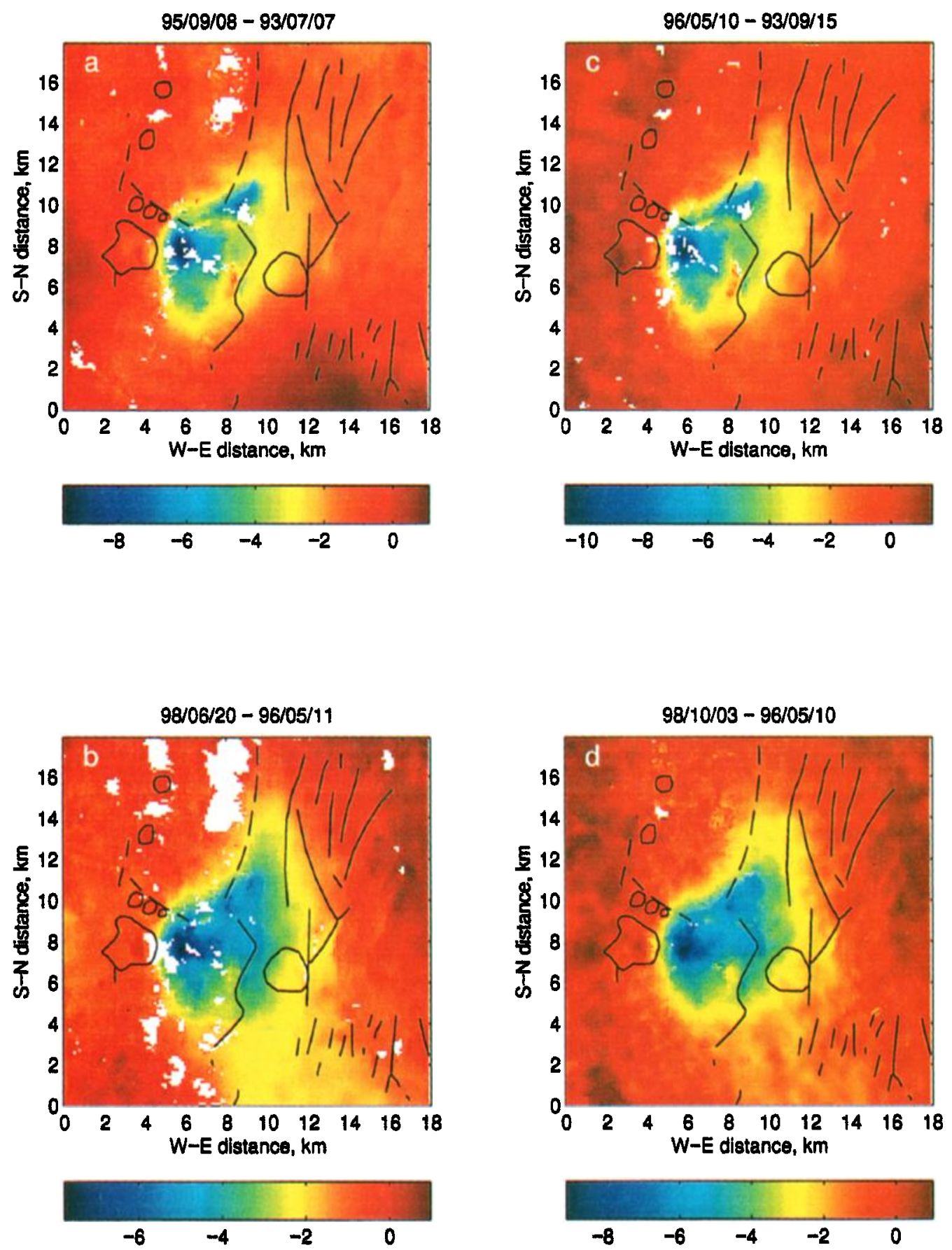

Plate 1. Four long-term interferometric pairs depicting ground deformation in the Coso geothermal field: (a) September 8, 1995/July 7, 1993, (b) June 20, 1998/May 11, 1996, (c) May 10, 1996/September 15, 1993, and (d) October 3, 1998/May 10, 1996. Reference frame in all interferograms is the same as in Figure 3. Interferometric pairs were filtered, unwrapped, averaged over $4 \times 4$ pixel bins, and converted from the phase difference in radians to the line of sight displacements in centimeters. White spots mark areas of decorrelation and/or layovers due to topographic slopes steeper than the $\sim 23^{\circ}$ incidence angle of the radar. 
As one can see from Table 1, point sources fit the data less successfully than finite spheroidal sources (this result might be expected because of a greater number of degrees of freedom associated with a finite spheroidal source model). Therefore we choose a combination of pressurized finite prolate ellipsoids of an arbitrary orientation [Yang et al., 1988] as basis functions for our simulations. We invert the observed surface displacements (Plate 1) for the positions, geometry, and strengths of multiple spheroidal pressure sources in an elastic half-space using Levenberg-Marquardt nonlinear least squares algorithm [Dennis and Schnabel, 1983]. While the Yang et al. [1988] model assumes a flat surface of an elastic half-space, we simulate the contributions of topography by allowing the source depths to vary with local relief at a point of observation [e.g., Williams and Wadge, 1998]. (Calculations neglecting topographic effects were performed as well; they yielded results similar to those presented below.) Each spheroidal source is characterized by eight degrees of freedom, namely, three spatial coordinates of the spheroid center $x_{o}, y_{o}$, and $z_{o}$, constant excess pressure within a spheroid $\Delta P$ (i.e., the difference between the source pressure and the ambient lithostatic pressure), major and minor axes of a spheroid $a$ and $b$, and strike and dip of the major axis $\phi_{a}$ and $\theta_{a}$, respectively. Inversions including variable number of sources $N$ indicate that increases in $N$ cease to produce a significant improvement in the data fit for $N>4-5$ (Table 1). Below we report the inversion results for $N=5$. Thus each inversion amounts to a 41-parameter fit ( $m=5 \times 8$ plus a constant line of sight shift). In the process of inversion, displacements at the free surface of a half-space are computed by superposing solutions for individual sources. Source interaction (e.g., a modification of the constant pressure boundary condition at a source surface due to other sources) is neglected. Superposed vertical and horizontal surface displacements are projected on a look vector of a satellite to compute the radar line of sight displacements. Iterations continue until the relative reduction in the mean square misfit $R$ (equation (1)) becomes less than $10^{-3}$ [Press et al., 1992, p. 685]. Results of the inversion for the interferometric pairs May 10, 1996/September 15, 1993, and October 3, 1998/May 10, 1996, are shown in Plates 2 and 3, respectively, and summarized in Table 2.

The source depths obtained from the inversions range from 1 to $3 \mathrm{~km}$ (Table 2). These depths correspond to the production depths of the Coso geothermal plant [Wohlet $z$ and Heiken, 1992; Feng and Lees, 1998]. In the model of deformation that occurred between between September 15, 1993, and May 10, 1996, sources 1 and 2 (see Plate 2) are responsible for the maximum subsidence amplitudes, while the deeper and larger source 3 accounts for the the bulk of the subsidence volume. The depth of $3 \mathrm{~km}$ inferred for the source 3 in the result of our inversion may in fact be an upper limit, because deformation similar to that due to a prolate spheroid can be also produced by a horizontal oblate (i.e., cracklike) deformation source located at a shallower depth

Table 2. Source Parameters Obtained From the Inversion

\begin{tabular}{|c|c|c|c|c|c|}
\hline \multirow[t]{2}{*}{ Parameters } & \multicolumn{5}{|c|}{ Sources } \\
\hline & 1 & 2 & 3 & 4 & 5 \\
\hline \multicolumn{6}{|c|}{ Interferometric pair May 10, 1996/September 15, 1993} \\
\hline$x_{o}, \mathrm{~km}$ & $5.50 \pm 0.01$ & $8.19 \pm 0.03$ & $9.02 \pm 0.04$ & $6.05 \pm 0.02$ & $7.44 \pm 0.06$ \\
\hline$y_{o}, \mathrm{~km}$ & $7.97 \pm 0.01$ & $10.15 \pm 0.01$ & $9.61 \pm 0.07$ & $6.95 \pm 0.07$ & $4.82 \pm 0.13$ \\
\hline Depth $z_{o}, \mathrm{~km}$ & $0.97 \pm 0.01$ & $0.94 \pm 0.01$ & $3.08 \pm 0.04$ & $2.00 \pm 0.04$ & $1.17 \pm 0.09$ \\
\hline$\Delta P / \mu \times 10^{5}, \mathrm{~Pa}$ & $-476.2 \pm 631.0$ & $-8.4 \pm 16.1$ & $-3.3 \pm 3.5$ & $-7.9 \pm 5.5$ & $3.2 \pm 2.9$ \\
\hline Major axis $a, \mathrm{~km}$ & $0.67 \pm 0.04$ & $1.78 \pm 0.06$ & $6.58 \pm 0.12$ & $3.27 \pm 0.12$ & $2.49 \pm 0.13$ \\
\hline Minor axis $b, \mathrm{~km}$ & $0.17 \pm 0.11$ & $0.48 \pm 0.47$ & $1.46 \pm 0.79$ & $1.03 \pm 0.36$ & $0.68 \pm 0.29$ \\
\hline Strike $\phi_{a}$, deg & $354.4 \pm 2.3$ & $243.7 \pm 0.4$ & $9.3 \pm 0.5$ & $355.9 \pm 0.7$ & $200.9 \pm 0.9$ \\
\hline Plunge $\theta_{a}$, deg & $2.9 \pm 2.4$ & $0.3 \pm 0.8$ & $9.4 \pm 0.5$ & $8.5 \pm 1.9$ & $2.2 \pm 1.2$ \\
\hline \multicolumn{6}{|c|}{ Interferometric Pair October 3, 1998/May 10, 1996} \\
\hline$x_{o}, \mathrm{~km}$ & $5.68 \pm 0.03$ & $7.29 \pm 0.05$ & $8.91 \pm 0.03$ & $5.87 \pm 0.17$ & $6.35 \pm 0.36$ \\
\hline$y_{0}, \mathrm{~km}$ & $7.81 \pm 0.02$ & $9.84 \pm 0.05$ & $9.08 \pm 0.10$ & $5.38 \pm 0.07$ & $5.56 \pm 0.29$ \\
\hline Depth $z_{o}, \mathrm{~km}$ & $2.09 \pm 0.06$ & $0.83 \pm 0.03$ & $2.66 \pm 0.04$ & $1.80 \pm 0.12$ & $2.52 \pm 0.36$ \\
\hline$\Delta P / \mu \times 10^{5}, \mathrm{~Pa}$ & $-70.1 \pm 41.9$ & $-3.8 \pm 26.0$ & $-2.7 \pm 2.1$ & $-82.6 \pm 121.1$ & $13.4 \pm 122.7$ \\
\hline Major axis $a, \mathrm{~km}$ & $1.89 \pm 0.07$ & $2.91 \pm 0.17$ & $6.56 \pm 0.12$ & $0.98 \pm 0.39$ & $2.75 \pm 0.69$ \\
\hline Minor axis $b, \mathrm{~km}$ & $0.56 \pm 0.17$ & $0.51 \pm 1.81$ & $1.56 \pm 0.61$ & $0.32 \pm 0.23$ & $0.48 \pm 2.16$ \\
\hline Strike $\phi_{a}$, deg & $100.3 \pm 7.6$ & $312.9 \pm 0.5$ & $182.4 \pm 0.5$ & $284.3 \pm 5.0$ & $237.9 \pm 5.8$ \\
\hline Plunge $\theta_{a}$, deg & $76.7 \pm 1.1$ & $0.8 \pm 1.0$ & $5.6 \pm 0.5$ & $0.3 \pm 16.0$ & $44.2 \pm 5.8$ \\
\hline
\end{tabular}

Parameter uncertainties represent diagonal elements of the estimated covariance matrix of the standard errors in the fitted parameters. Source depths, $z_{o}$, are given with respect to local elevations of the source epicenters $\left(x_{0}, y_{0}\right)$. We assume the Poisson's ratio of 0.25 in all calculations. 

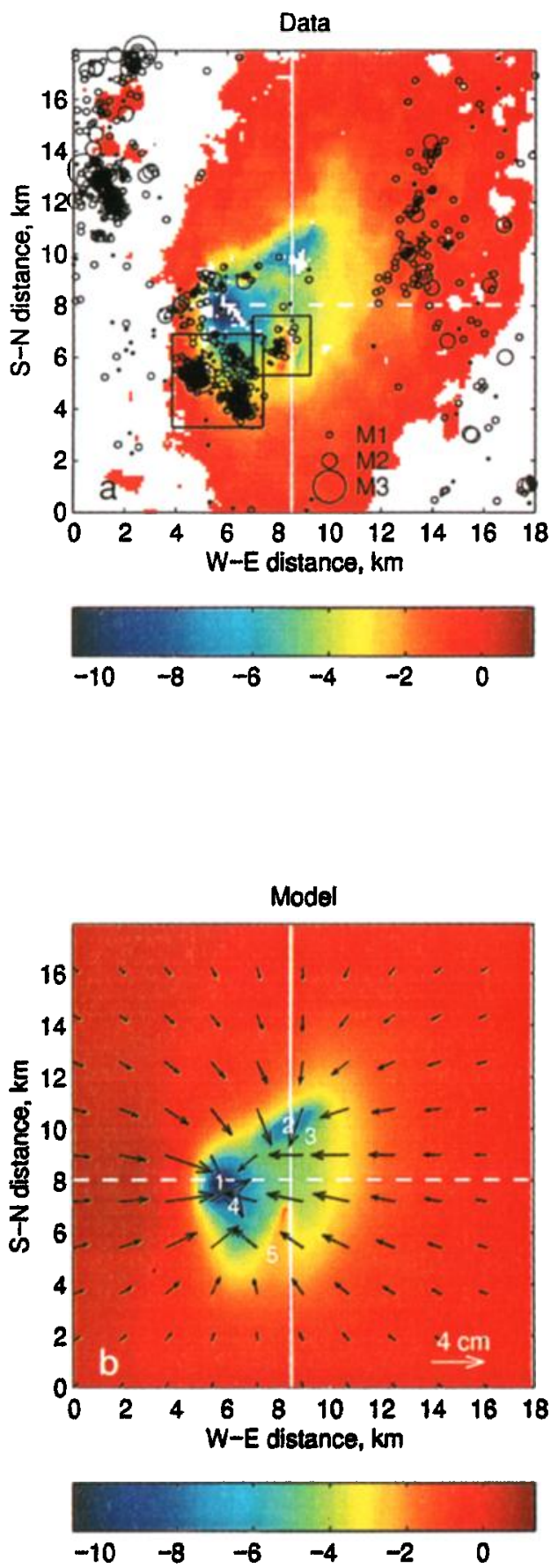
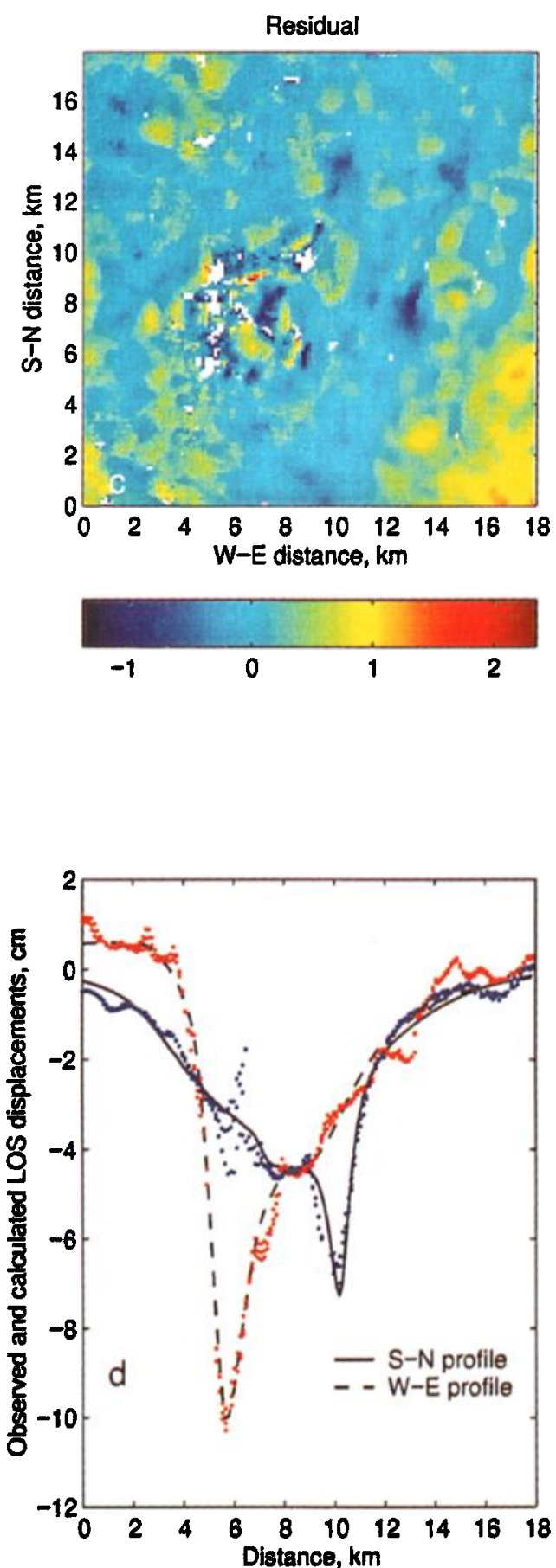

Plate 2. (a) Observed line of sight (LOS) displacements, in centimeters, for the time interval September 15, 1993, to May 10, 1996. Circles denote shallow earthquakes (hypocenter depths $<5 \mathrm{~km}$ ) that occurred in the map area during the same time period. Rectangles outline earthquake swarms associated with the deformation anomaly. White lines denote profiles shown in Plate 2d. Areas of image decorrelation and presumed atmospheric noise (in particular, positive LOS displacements on the edges of the interferogram, see Plate 2a and main text) are shown in white; data from these areas were not included in the inversions. (b) Best fitting model obtained from the inversion. Numbers mark projections of the centers of spheroidal pressure sources onto the surface. Source parameters are given in Table 2. Arrows denote horizontal displacements predicted by the model. (c) Residual LOS displacements produced by subtracting the model (Plate 2b) from the data (Plate 2a). (d) South-north (blue dots, solid line) and west-east (red dots, dashed line) profiles across the deformation anomaly. Dots are the observed, and lines are the calculated line of sight displacements along the profiles shown in Plates $2 \mathrm{a}$ and $2 \mathrm{~b}$. For each along-profile coordinate, the observed LOS displacements are plotted for 3 pixels adjacent to a profile (pixel size is $120 \times 120 \mathrm{~m}$ ). 

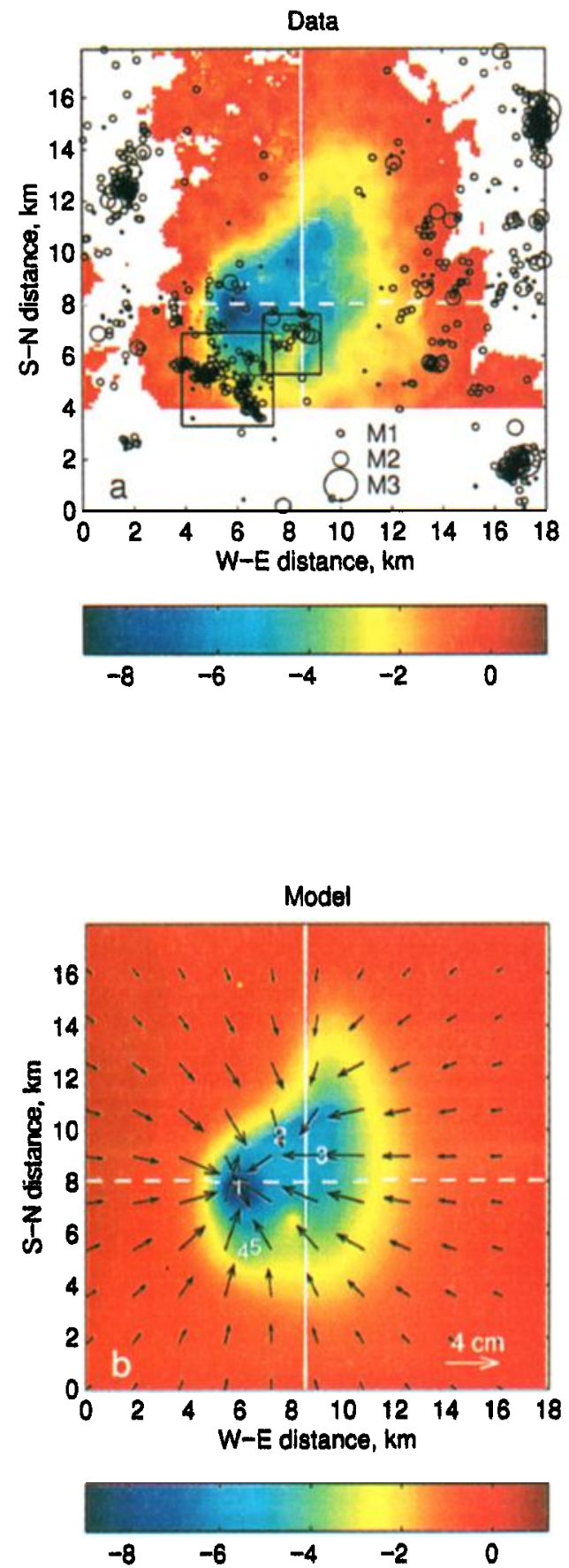
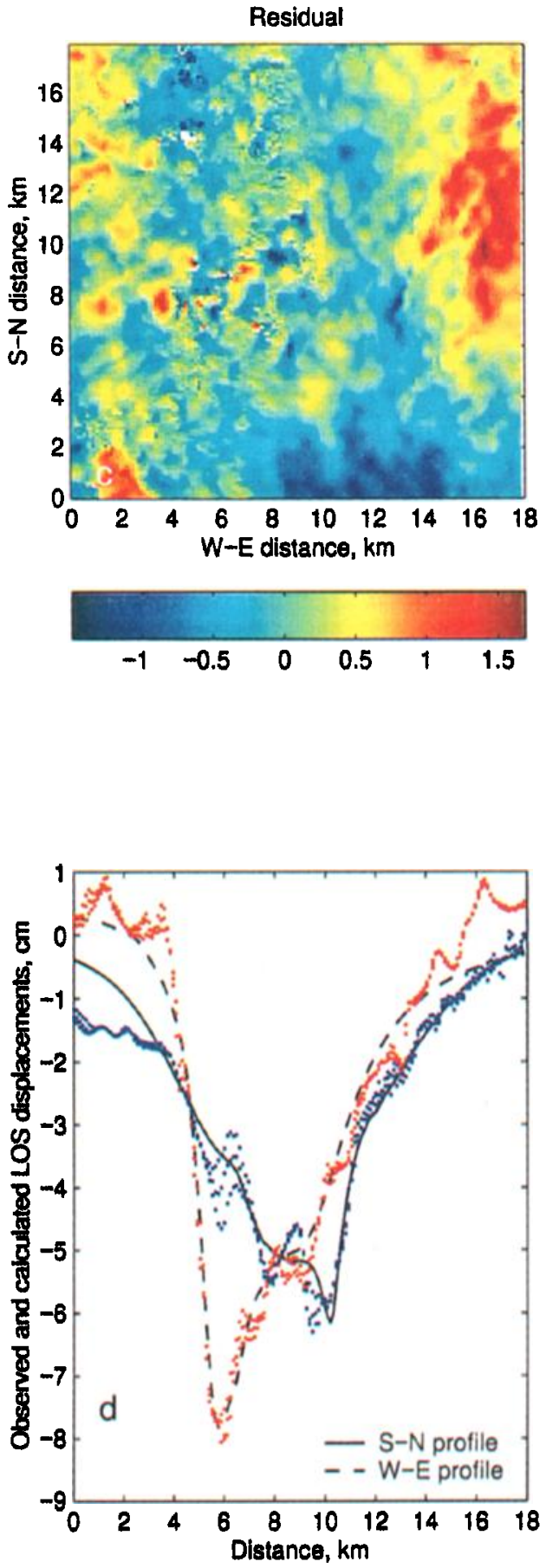

Plate 3. Same as Plate 2, for the time interval May 10, 1996, to October 3, 1998. Positive LOS displacements are presumed to be due to atmospheric effects (Plate 3a) and not included in the inversion. The southern extension of the subsidence anomaly (see Plates $3 \mathrm{a}$ and $2 \mathrm{a}$ ) is assumed to be of a shallow origin and also excluded from the inversion. This gave rise to relatively large residuals in the eastern and southwestern parts of the area of study, as seen in Plates $3 \mathrm{c}$ and $\mathbf{3 d}$. Note a broadening of the subsidence peak corresponding to the source 1 compared with the time period September 15, 1993, to May 10, 1996 (Plate 2). 
(Y. A. Fialko et al., Deformations due to a pressurized horizontal circular crack in an elastic half-space, with applications to volcano geodesy, Part 1, Theory, submitted to Geophysical Journal International, 2000). Crack-like source geometries are not incorporated in our inversion routine as, to the best of our knowledge, accurate solutions for elliptical cracks in an elastic half-space are not yet available.

As mentioned above, addition of sources 4 and 5 only slightly reduces the misfit between the model and the data (Table 1). Source 4 models what seems to be a southern extension of the main subsidence peak (source 1 ), and source 5 (the only source representing a dilation rather than compaction) accounts for a local uplift in the southern part of the subsidence bowl (see Plates 1 and 2). In the model for the October 3, 1998/May 10, 1996, pair (Plate 1), source 1 produces both the maximum subsidence amplitude and the maximum subsidence volume. Assuming an effective shear modulus $\mu=10 \mathrm{GPa}$, from Table 2 one may deduce the excess source pressures of the order of a few hundreds of kilopascals to a few megapascals (note that a negative $\Delta P$ corresponds to underpressure). The only exception is the excess pressure of source 1 , which is inferred to be of the order of several tens of megapascals between 1993 and 1996. This excess pressure is of the order of the rock tensile strength and may be too high if interpreted at face value. However, in the model considered, the source excess pressure $\Delta P$ may be dependent on the inferred source volume $V$ [e.g., Davis, 1986]. For a point source the excess source pressure and the source volume cannot be determined independently from the inversion of the surface displacement data as the source "strength" is characterized by a product $\Delta P \times V$. The finite spheroid model in principle allows the determination of the characteristic source dimensions provided they are nonnegligible compared to the source depth (note, however, that the Yang et al. [1988] model becomes inaccurate when the radius of curvature of the upper surface of a spheroidal source becomes comparable to the source depth). If the characteristic source dimensions are much smaller than the source depth (i.e., $a, b<<z_{o}$ ), they become subject to trade-offs with the excess source pressure, as in the case of a point source. This likely explains large uncertainties in $\Delta P$ and $b$ inferred from the inversion for some sources (e.g., sources 2 and 4 , see Table 1), as well as unrealistically high values of the excess pressure $\Delta P$ inferred for source 1 . Unfortunately, in situ measurements of fluid pressures in the production wells of the Coso geothermal plant are proprietary and not available for comparison with our modeling results. Note that if the data on the excess fluid pressures were available, our modeling results could provide constraints on the volumes of the reservoir rocks subjected to these excess pressures.

\section{Discussion}

Published data suggest that ground subsidence may be a common feature in geothermal production ar- eas [Narasimhan and Goyal, 1984; Massonnet et al., 1997; Vadon and Sigmundsson, 1997; Carnec and Fabriol, 1999]. Possible physical causes of volume changes causing subsidence include depletion of fluid storage, thermal contraction, and host rock compaction (e.g., pore collapse) due to decreasing pore pressures [e.g., Narasimhan and Goyal, 1984]. Compaction is unlikely to be the cause of the observed deformation in Coso as the geothermal reservoir there is composed of igneous rocks with permeability predominantly controlled by fractures [Bishop and Bird, 1987]. Both reduction in the reservoir pressure and thermal contraction could contribute to the observed subsidence pattern. The average cooling rate $\dot{T}$ required to produce the observed deformation can be estimated as follows:

$$
\dot{T} \sim \frac{\dot{V}_{s}}{\alpha V_{0}},
$$

where $\alpha$ is a coefficient of thermal expansion of the host rocks, $V_{0}$ is the volume of the host rocks that undergo cooling (as an approximation, we assume that $V_{0}$ is constant), and $\dot{V}_{s}$ is the volumetric rate of surface subsidence taken as a proxy for the contraction rate due to cooling. Using typical values of the coefficient of thermal expansion for silicate rocks, $\alpha \sim O\left(10^{-5}\right)$ $\mathrm{K}^{-1}$, where $\mathrm{K}$ is a degree kelvin, the observed volumetric subsidence rates of the order of $10^{6} \mathrm{~m}^{3} \mathrm{yr}^{-1}$ might be produced by the bulk cooling rates of a few degrees to a few tens of degrees per year provided that the the reservoir volumes affected by cooling, $V_{0}$, are a few tens of cubic kilometers to a few cubic kilometers, respectively. Assuming that the geothermal plant efficiency $\epsilon$ is of the order of a few percent, the rate of the thermal energy loss $\dot{E}$ inferred from the reservoir subsidence, $\dot{E}=c \rho \dot{V}_{s} \alpha^{-1}$, where $c$ is the heat capacity and $\rho$ is the host rock density, is sufficient to maintain the generation of $\epsilon \dot{E} \approx 300 \mathrm{MW}$ of electricity (i.e., the capacity of the geothermal plant [Wohletz and Heiken, 1992]).

While the above arguments imply that a substantial part of the observed subsidence may be caused by thermal contraction alone, the localized nature of the subsidence peaks, as well as the existence of a dilatational source (source 5 in Plates 2 and 3 and in Table 2) suggest that pore pressure variations are likely to be involved in producing the observed deformation, at least locally. Correlation between subsidence and reservoir pressure drop is well documented in several geothermal production areas, for example in the Geysers [Lofgren, 1978] and Cerro Prieto [Carnec and Fabriol, 1999] geothermal fields. It is interesting to note that in both of the mentioned locations local uplifts similar to that shown in Plates 2 and 3 were observed. These uplifts have been attributed to the elevated fluid pressures caused by reinjection of the steam condensate back to the reservoir [Lofgren, 1978; Carnec and Fabriol, 1999]. In principle, increases in pore pressures resulting from fluid injection may reduce the effective normal stress and increase the tendency for failure along the suitably oriented slippage planes [Pearson, 1981; Fehler, 1989]. 
In the Coso area, microseismicity clearly exhibits clustering of microearthquakes in the area of relative uplift in the southern part of subsidence bowl (represented by source 5 in our models, see Plates 2a and 3a). This is consistent with the inferred uplift being a result of pore pressure increases due to injection of condensate. We believe that clusters of earthquakes to the south-west of the local uplift (i.e., at the southernmost tip of the subsidence anomaly, see Plates 2 and 3) also result from fluid reinjection into the reservoir. This area (outlined by a larger rectangle in Plates 2a and 3a) has the highest concentration of development wells in the Coso geothermal field [Feng and Lees, 1998]. The fluid reinjection in this area, however, is not conspicuously expressed in a relative surface uplift. Strong clustering of microseismicity around the regions of steam extraction and fluid injection has been observed in other geothermal production areas [Narasimhan and Goyal, 1984]. Majer and McEvilly [1979] suggested that a microearthquake activity can also be caused by volume changes due to fluid withdrawal and subsidence.

To address the question to what extent (if any) the geothermal production in Coso affects the microearthquake activity, we analyzed the pattern of seismicity in the area of study prior to the commencement of geothermal recovery. Figure 4 shows epicenters of earthquakes shallower than $5 \mathrm{~km}$ that occurred in the area during 1980-1987. By comparing Figure 4 to Plates 2a and 3a

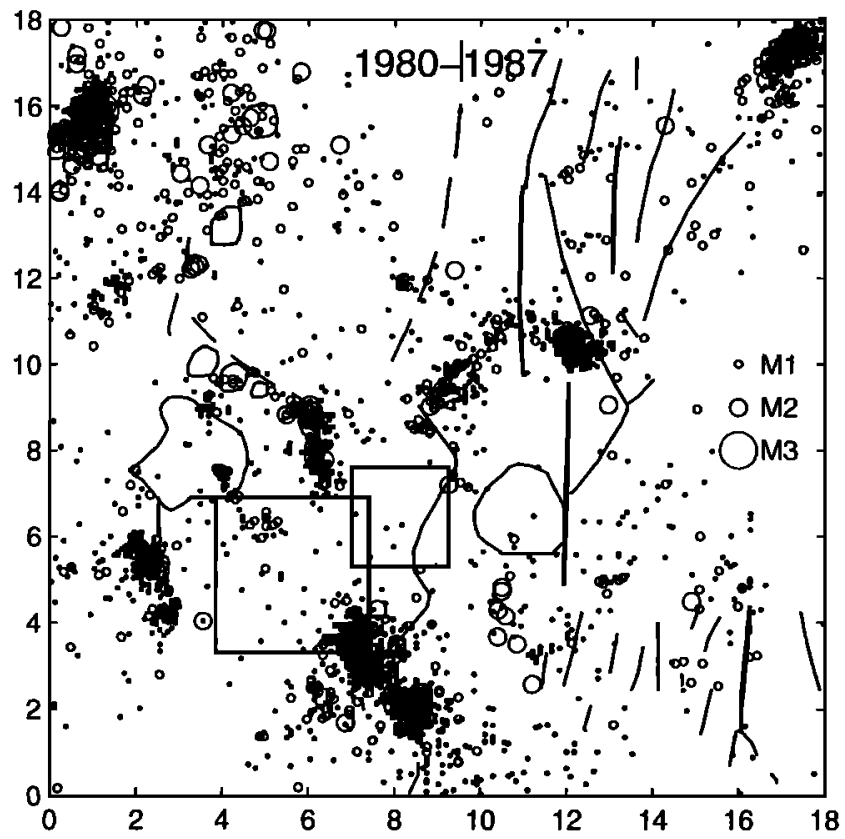

Figure 4. Distribution of shallow (depth $<5 \mathrm{~km}$ ) earthquakes in the Coso area during 1980-1987. Circles on the right denote the magnitude scale. Rectangles outline the areas of seismicity associated with deformation due to the geothermal production, as in Plates 2a and 3a. Note the lack of earthquake activity inside the outlined areas during 1980-1987 (i.e., before the production commencement).

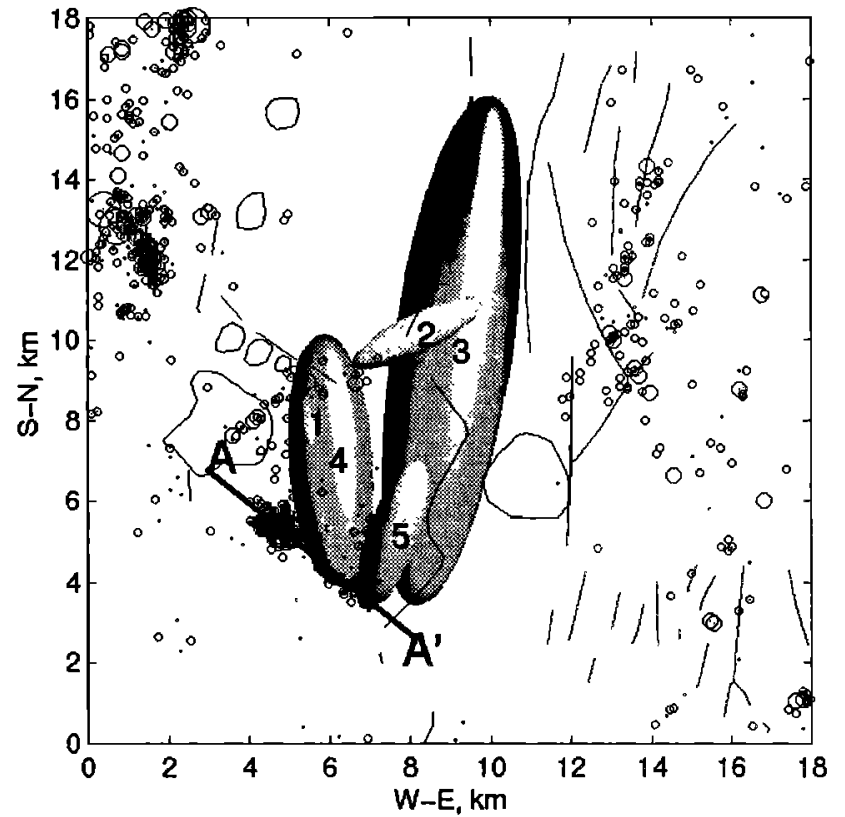

Figure 5. Geometry of the deformation sources obtained in the result of the inversion of the InSAR data collected between 1993 and 1996. Notation is the same as in Plate 2 and Table 2. Line A- $\mathrm{A}^{\prime}$ denotes a seismicity trend apparent from Plates 2 and 3 and 4.

one can see that the areas of most intense seismicity associated with the deformation anomaly are not conspicuous on the 1980-1987 seismicity map. Therefore it is likely that the current concentration of seismicity at the southern edge of a subsidence bowl is induced by the geothermal plant activity. Note that the microearthquake clusters in the larger box shown in Plates 2a and 3a seem to be aligned along a northwest trend that is also apparent in the seismicity pattern prior to 1987 (Figure 4) [see also Walter and Weaver, 1980]. NW-SE alignment of the earthquake epicenters may manifest a subvertical fault (or system of faults) that was apparently brought on the verge of failure in the vicinity of the geothermal production area. One possible mechanism by which geothermal production can decrease the effective shear strength of preexisting weakness planes relates to increases in the pore fluid pressure due to fluid injection, as discussed above. Here we will evaluate the direct effect of changes in the normal and shear stresses due to the geothermal reservoir deformation deduced from the InSAR data. In general, contraction of the geothermal reservoir tends to decrease normal stress on the planes that are tangential to the surface subsidence anomaly [e.g., Thatcher and Savage, 1982]. Provided that the deformation occurs slowly compared to the characteristic relaxation time for pore fluid pressure (i.e., at essentially drained conditions [Rice and Cleary, 1976]), this decrease in normal stress is able to reduce effective shear strength on suitably oriented fracture planes. Figure 5 shows the geometry of the deformation sources inferred from our 
inversions for the interferometric pair 1993 and 1996 (see Plate 2 and Table 2), and a projection of a hypothesized fault plane on the surface (line A- $\mathrm{A}^{\prime}$ in Figure 5). Normal and maximum shear stresses resolved on that plane due to the spheroidal pressure sources are shown in Figure 6 along with the earthquakes that occurred within $1 \mathrm{~km}$ from the plane $\mathrm{A}-\mathrm{A}^{\prime}$ during the respective time period. Decreases in normal stress are taken to be positive. Although the earthquake locations may be uncertain up to $1 \mathrm{~km}$, in general, the earthquake clusters occur in the areas where normal stress is decreased and maximum shear stress is increased by a few hundreds of kilopascals. Static stress perturbations of this magnitude have been suggested to be significant for earthquake triggering in seismically active areas [e.g., King et al., 1994]. Results similar to those shown in Figure 6 were also obtained for the time period from 1996 to 1998.

Feng and Lees [1998] calculated principle stresses in the Coso area by using earthquake focal mechanisms
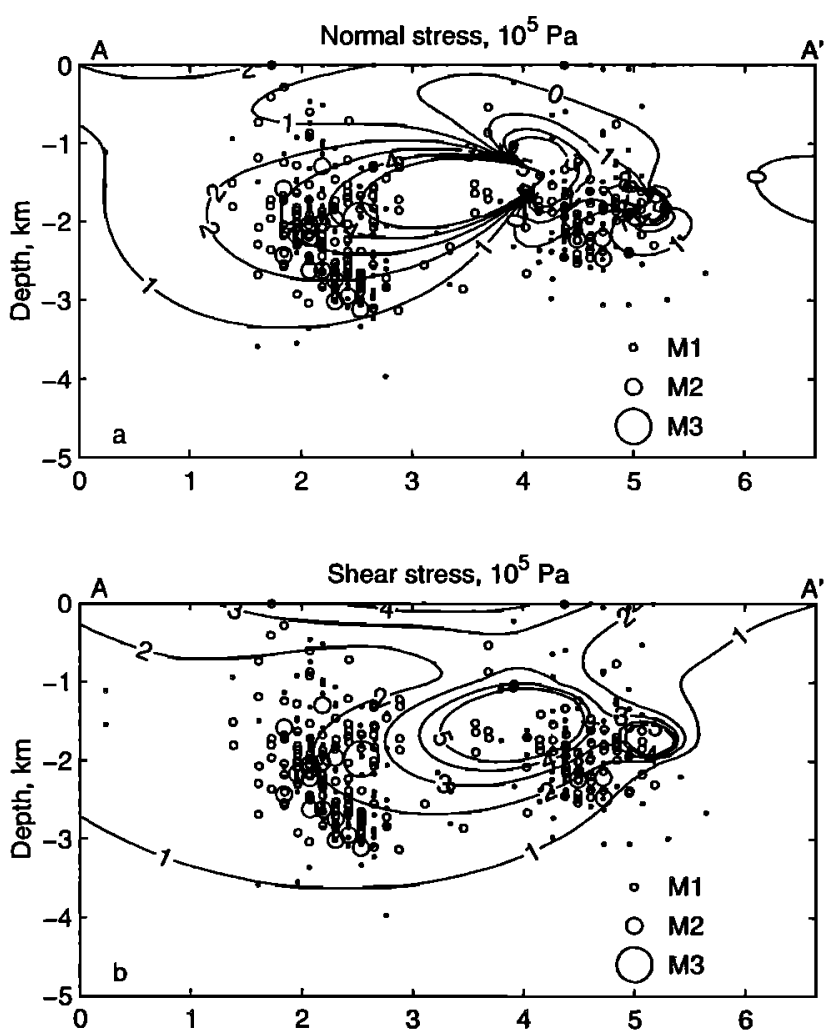

Figure 6. Calculated normal and maximum shear stress induced on the plane $A-A^{\prime}$ (see Figure 5) by the deformation sources inferred from the inversion of the InSAR data. Circles denote earthquake locations. Alignment of seismicity in vertical streaks is an artifact of the earthquake coordinate round-off errors. Stress contour lines have units of $10^{5} \mathrm{~Pa}(1 \mathrm{bar})$. Decreases in the normal stress are taken to be positive. Note that the stress calculations become inaccurate in the regions where the deformation sources intersect the $\mathrm{A}-\mathrm{A}^{\prime}$ plane; these regions are approximately outlined by the maximum shear stresses $>3 \times 10^{5} \mathrm{~Pa}$. and identified a transition from a transtensional regime within the geothermal production area to a transpressional regime on its periphery. They found that the orientation of the principle stresses may change quite abruptly on a spatial scale of $<1 \mathrm{~km}$, and concluded that for this reason the neighboring earthquake clusters occur "in geologically isolated blocks" [Feng and Lees, 1998, p. 243]. However, comparison of stress inversions of Feng and Lees [1998] with our results indicates that the nearly vertical orientation of the maximum compressive stress within the geothermal field may be explained by horizontal extension at depth due to the reservoir subsidence and concomitant bending of the overlying strata. In particular, a transition in the focal mechanisms between the earthquake clusters shown in Figure 6 and the earthquakes immediately to the north (clusters COSO-SW, COSO-SE, and COSO-NW in the notation of Feng and Lees [1998]) essentially coincides with the southern boundary of the subsidence anomaly (see Plates 2a and 3a).

Comparison of consecutive interferograms (e.g., Plates 1a, 1b, and 1c, 1d) indicates that the main subsidence peaks broaden with time and may even overlap on the interferograms corresponding to the time period from 1996 to 1998 . This is manifested in general increases in the source depths and/or volumes inferred from our inversions (see Table 2). To further test this temporal variability in the geometry of the subsurface geothermal reservoir, we performed a series of inversions in which the spheroid shapes and positions were assumed to be constant in time but the excess source pressures were allowed to vary. These simulations gave rise to a somewhat poorer fit to the data than individual inversions shown in Plates 2 and 3. However, we point out that the inherent nonuniqueness of the inversions, uncertainties in the data, and idealizations implicit in our forward models do not allow a robust determination of the timedependent evolution of the deformation sources beneath the Coso geothermal area. As discussed above, the inferred broadening of the subsidence anomalies may reflect deepening and/or lateral expansion of the deformation sources and (in some average sense) an increase in the reservoir volume affected by the geothermal production. These effects may be caused by progressive cooling and thermal contraction of the host rocks and/or decreases in the reservoir pressure due to fluid withdrawal. Further advances in understanding the mechanisms of deformation in the Coso geothermal field may be made if the in situ measurements of pressures and temperatures within the geothermal system become available. For example, borehole records may help to determine the origin of the observed ground subsidence (e.g., thermal contraction vs. fluid loss), and constrain the volumes of the reservoir rocks affected by stress perturbations due to the geothermal energy production. Regardless of whether the observed ground displacements in the production area of the Coso geothermal plant are caused by temperature or pore fluid pressure ef- 
fects, the deformation sources inferred from the inversions of geodetic data (e.g., Figure 5) likely represent regions of an enhanced fluid circulation (and, perhaps, an increased permeability of the host rocks) within the geothermal reservoir. In principle, this conclusion may be tested using geophysical (e.g., seismic or geoelectric) techniques. Investigations of the seismic velocity, attenuation, and anisotropy structure of the Coso geothermal area [Wu and Lees, 1999; Lees and $W u, 1999]$ reveal anomalous regions that can be broadly related to our inferred deformation sources, but more detailed comparisons are required to establish possible spatial correlations between the inferred seismic and geodetic anomalies.

\section{Conclusions}

InSAR observations of ground deformation associated with geothermal heat production in the Coso geothermal area reveal a broad subsidence over $\sim 50 \mathrm{~km}^{2}$, with two localized subsidence peaks separated by several kilometers in the western and northeastern part of the anomaly and a relative uplift at the southern edge of the subsidence bowl. This subsidence likely results from the geothermal reservoir cooling and/or depletion. The inferred subsidence rate is $\sim 3-4 \mathrm{~cm} \mathrm{yr}^{-1}$ in the peak of the anomaly, and the average volumetric subsidence rate is $\sim 10^{6} \mathrm{~m}^{3} \mathrm{yr}^{-1}$. Such deformation may be typical for many exploited geothermal fields. We model the Earth surface displacements inferred from the InSAR data using a combination of spheroidal pressure sources in an elastic half-space. Source depths obtained from our modeling range from 1 to $3 \mathrm{~km}$, coinciding with the production depths of the Coso geothernal plant. Analysis of consecutive interferograms shows that the subsidence peaks broaden with time, which may indicate the increasingly larger and/or deeper parts of the geothermal reservoir are affected by the geothermal production. Simulations of the stress state in the upper crust based on our inversion results suggest that a signifcant fraction of seismicity induced by the geothermal plant operation may result from perturbations in the effective stress caused by fluid injection and contraction of the geothermal reservoir. Our modeling results point out that a transition from a transtensional stress regime within the geothermal area to a transpressional regime on its periphery inferred from inversions of the earthquake focal mechanisms may be due to flexure of the uppermost crust associated with geothermal subsidence.

Acknowledgments. The authors thank Alan Linde, Jonahtan Lees, and Paul Lundgren for thoughtful reviews that improved the quality of this manuscript and Egill Hauksson for providing the earthquake data and fault maps for the Coso area. Paul Davis and Paul Lundgren kindly shared their computer codes for the inversion of geodetic. data. The ERS SAR imagery has been acquired under research user category from Eurimage, Italy. Digital elevation maps, InSAR measurements of the line of sight displace- ments, and modeling data used in this study are available from the authors. Contribution number 8690 of the Division of Geological and Planetary Sciences, Seismological Laboratory, California Institute of Technology.

\section{References}

Austin, C. F., and J. K. Pringle, Geologic investigations at the Coso thermal area, Tech. Publ. 4878, pp. 40, Nav. Weapons Cent., China Lake, Calif., 1970.

Bishop, B. P., and D. K. Bird, Variation in sericite compositions from fracture zones within the Coso Hot Springs geothermal system, Geochim. Cosmochim. Acta, 51, 1245-1256, 1987.

Carnec, C., and H. Fabriol, Monitoring and modeling land subsidence at Cerro Prieto geothermal field, Baja California, Mexico, using SAR interferometry, Geophys. Res. Lett., 26, 1211-1214, 1999.

Combs, J., Heat flow in the Coso Geothermal Area, Inyo County, California, J. Geophys. Res., 85, 2411-2424, 1980.

Davis, P. M., Surface deformation due to inflation of an arbitrarily oriented triaxial ellipsoidal cavity in an elastic half-space, with reference to Kilauea Volcano, Hawaii, $J$. Geophys. Res., 91, 7429-7438, 1986.

Dennis, J. E., and R. B. Schnabel, Numerical Methods for Unconstrained Optimization and Nonlinear Equations, 378 pp., Prentice-Hall, Englewood Cliffs, N. J., 1983.

Duffield, W. A., C. R. Bacon, and G. B. Dalrymple, Late Cenozoic volcanism, geocronology, and structure of the Coso Range, Inyo county, California, J. Geophys. Res., 85, 2381-2404, 1980.

Fehler, M. C., Stress control of seismicity patterns observed during hydraulic fracturing experiments at the Fenton Hill Hot Dry Rock Geothermal Energy Site, New Mexico, Int. J. Rock Mech. Min. Sci. Geomech. Abstr., 26, 211-219, 1989.

Feng, Q., and J. M. Lees, Microseismicity, stress, and fracture pattern within the Coso geothermal field, Tectonophysics, 289, 221-238, 1998.

Fielding, E. J., R. G. Blom, and R. M. Goldstein, Rapid subsidence over oil fields measured by SAR interferometry, Geophys. Res. Lett., 25, 3215-3218, 1998.

Gabriel, A. K., R. M. Goldstein, and H. A. Zebker, Mapping small elevation changes over large areas: Differential radar interferometry, J. Geophys. Res., 94, 9183-9191, 1989.

Goldstein, R. M., Atmospheric limitations to repeat-track radar interferometry, Geophys. Res. Lett., 22, 2517-2520, 1995.

Goldstein, R. M., H. Engelhardt, B. Kamb, and R. Frolich, Satellite radar interferometry for monitoring ice sheet motion: Application to an Antarctic ice stream, Science, 262, 1525-1530, 1993.

Hauksson, E., K. Hutton, H. Kanamori, L. Jones, J. Mori, S. Hough, and G. Roquemore, Preliminary report on the 1995 Ridgecrest earthquake sequence in eastern California, Seismol. Res. Lett., 66, 54-60, 1995.

King, G. C. P., R. S. Stein, and J. Lin, Static stress changes and the triggering of earthquakes, Bull. Seismol. Soc. $A m .$, 84, 935-953, 1994.

Lanari, R., P. Lundgren, and E. Sansosti, Dynamic deformation of Etna volcano observed by satellite radar interferometry, Geophys. Res. Lett., 25, 1541-1544, 1998.

Lanphere, M. A., B. Dalrymple, and R. L. Smith, K-Ar ages of Pleistocene rhyolitic volcanism in the Coso Mountains, California, Geology, 3, 339-341, 1975.

Lees, J. M., and $\mathrm{H}$. Wu, $\mathrm{P}$ wave anisotropy, stress, and crack distribution at Coso Geothermal Field, California, J. Geophys. Res., 104, 17,955-17,973, 1999. 
Lofgren, B. E., Monitoring crustal deformation in the Geysers-Clear Lake geothermal system, California, U.S. Geol. Surv. Open File Rep., 78-597, 1978.

Majer, E. L., and T. V. McEvilly, Seismological investigations at the Geysers Geothermal Field, Geophysics, 44, 246-269, 1979.

Massonnet, D., and K. Feigl, Discrimination of geophysical phenomena in satellite radar interferograms, Geophys. Res. Lett., 22, 1537-1540, 1995.

Massonnet, D., and K. Feigl, Radar interferometry and its application to changes in the Earth's surface, Rev. Geophys., 36, 441-500, 1998.

Massonnet, D., T. Holzer, and H. Vadon, Land subsidence caused by the East Mesa Geothermal Field, California, observed using SAR interferometry, Geophys. Res. Lett., 22, 1537-1540, 1997.

Mogi, K., Relations between the eruptions of various volcanoes and the deformations of the ground surfaces around them, Bull. Earthquake Res. Inst. Univ. Tokyo, 36, 99$134,1958$.

Narasimhan, T. N., and K. P. Goyal, Subsidence due to geothermal fluid withdrawal, in Man-Induced Land Subsidence, Rev. Eng. Geol., vol. 6, edited by T. L. Holzer, pp. 35-66, Geol. Soc. of Am., Boulder, Colo., 1984.

Pearson, C., The relationship between microseismicity and high pore pressure during hydraulic simulation experiments in low permeability rocks, J. Geophys. Res., 86, 7855-7864, 1981.

Press, W. H., S. A. Teukolsky, W. T. Vetterling, and B. P. Flannery, Numerical Recipes in C: The Art of Scientific Computing, 2nd ed., 994 pp., Cambridge Univ. Press, New York, 1992.

Reasenberg, P., W. Ellsworth, and A. Walter, Teleseismic evidence for a low-velocity body under the Coso Geothermal Area, J. Geophys. Res., 85, 2471-2483, 1980.

Rice, J. R., and M. P. Cleary, Some basic stress-diffusion solutions for fluid-saturated elastic porous media with compressible constituents, Rev. Geophys., 14, 227-241, 1976.

Roquemore, G., Structure, tectonics, and stress of the Coso Range, Inyo County, California, J. Geophys. Res., 85, 2434-2440, 1980.

Rosen, P. A., S. Hensley, H. A. Zebker, F. H. Webb, and E. J. Fielding, Surface deformation and coherence measurements of Kilauea volcano, Hawaii, from SIR-C radar interferometry, J. Geophys. Res., 101, 23,109-23,125, 1996.
Smith, R. L., and H. R. Shaw, Igneous-related geothermal systems, U.S. Geol. Surv. Circ., 726, 58-83, 1975.

Tarayre, H., and D. Massonnet, Atmospheric propagation heterogeneities revealed by ERS-1 interferometry, Geophys. Res. Lett., 23, 989-992, 1996.

Thatcher, W., and J. Savage, Triggering of large earthquakes by magma-chamber inflation, Geology, 10, 637-640, 1982.

Vadon, H., and F. Sigmundsson, Crustal deformation from 1992 to 1995 at the Mid-Atlantic Ridge, southwest Iceland, mapped by satellite radar interferometry, Science, 275, 193-197, 1997.

Walter, A. W., and C. Weaver, Seismicity of the Coso Range, California, J. Geophys. Res., 85, 2441-2458, 1980.

Williams, C. A., and G. Wadge, The effects of topography on magma chamber deformation models: Application to Mt. Etna and radar interferometry, Geophys. Res. Lett., 25, 1549-1552, 1998.

Wohletz, K., and G. Heiken, Volcanology and Geothermal Energy, Univ. of Calif. Press, Berkeley, 1992.

Wu, H., and J. M. Lees, Three-dimensional $P$ and $S$ wave velocity structures of the Coso Geothermal Area, California, from microseismic travel time data, J. Geophys. Res., 104, 13,217-13,233, 1999.

Yang, X.-M., P. M. Davis, and J. H. Dieterich, Deformation from inflation of a dipping finite prolate spheroid in an elastic half-space as a model for volcanic stressing, $J$. Geophys. Res., 93, 4249-4257, 1988.

Young, C.-Y., and R. W. Ward, Three-dimensional $Q^{-1}$ model of the Coso Hot Springs Known Geothermal Resource Area, J. Geophys. Res., 85, 2459-2470, 1980.

Zebker, H. A., and R. M. Goldstein, Topographic mapping from interferometric synthetic aperture radar observations, J. Geophys. Res., 91, 4993-4999, 1986.

Zebker, H. A., P. A. Rosen, and S. Hensley, Atmospheric effects in interferometric synthetic aperture radar surface deformation and topographic maps, J. Geophys. Res., 102, 7547-7563, 1997.

Y. Fialko and M. Simons, Seismological Laboratory, California Institute of Technology, Pasadena, CA 91125. (fialko@gps.caltech.edu; simons@caltech.edu)

(Received Nov. 17, 1999; revised Apr. 5, 2000; accepted May 5, 2000.) 